\title{
Associated Factors with Prolonged Stay in Pediatric Observation Ward of Urban University Hospital in Thailand
}

\author{
Aunchalee Chatgitisan1, Sakda Arj-Ong Valipakorn², Uthen Pandee ${ }^{3 *}$ \\ ${ }^{1}$ Department of Pediatrics Nursing, Faculty of Medicine Ramathibodi Hospital, Mahidol University, Bangkok, Thailand \\ ${ }^{2}$ Clinical Research Center, Faculty of Medicine Ramathibodi Hospital, Mahidol University, Bangkok, Thailand \\ ${ }^{3}$ Department of Pediatrics, Faculty of Medicine Ramathibodi Hospital, Mahidol University, Bangkok, Thailand \\ Email: *uthenp@hotmail.com
}

How to cite this paper: Chatgitisan, A., Valipakorn, S.A.-O. and Pandee, U. (2021) Associated Factors with Prolonged Stay in Pediatric Observation Ward of Urban University Hospital in Thailand. Open Journal of Nursing, 11, 132-138.

https://doi.org/10.4236/ojn.2021.113012

Received: January 20, 2021

Accepted: March 16, 2021

Published: March 19, 2021

Copyright $\odot 2021$ by author(s) and Scientific Research Publishing Inc. This work is licensed under the Creative Commons Attribution-NonCommercial International License (CC BY-NC 4.0). http://creativecommons.org/licenses/by-nc/4.0/

\begin{abstract}
Background: Pediatric observation ward $(\mathrm{OW})$ is the area where the patient can be monitored or have early investigation/management and observe part of emergency department (ED); patients are admitted to this area with an expectation of discharge within 24 hours. Observation ward was beneficial in preventing avoidable hospitalizations, due to the high volume of patients in $\mathrm{ED}$, OW increasing demands, overcrowding, and prolonged stay. Objective: This study aimed to examine the characteristics and factors associated with prolonged length of stay (LOS) more than 24 hours in the pediatric observation ward. General demographic data were recorded including age, sex, LOS, diagnosis and disposition. Results: This is a retrospective study of children 15 years old or younger who admit to Pediatric OW at urban university hospital and prolonged stay more than 24 hours during January 2014 to June 2015. There were 670 patients admitted at OW during the study period (median age of 5 years; 53\% were male). Mean length of stay in OW was 61 hours. The most common top 5 diagnoses were respiratory problem (32\%), gastrointestinal problem (29\%), infectious disease (11\%), neurological (7\%), and dental problem $(6 \%)$. The majority of patients were discharge home $602 / 670$ cases (90\%), and $10 \%$ (68/670 cases) were admitted to inpatient ward. There were 552 patients (82\%) who had prolonged OW more than 24 hours. Compared with the factors in both group, we found that the associated factor for prolonged OW stay was the age of patient, which seems to be younger in the prolonged stay group (median age of 4 years 3 months vs 3 years 5 months, $p$ $=0.04)$. Younger children had significant factors for prolonged stay in OW $(\mathrm{p}$ $<0.001)$ compared to all age categorized less than 1 year, 1 - 5 years, 5 - 10 years, $10-15$ years and more than 15 years respectively. Conclusion: This
\end{abstract}


was the study for report of pediatric observation ward utilization. The younger patient was the associated factor for prolonged stay in OW. Understanding this related issue will be the starting points for assessing patients carefully before admitting to OW for improving efficiency and quality of care in pediatric OW.

\section{Keywords}

Associated Factor, Prolonged Stay, Pediatric, Observation Ward

\section{Introduction}

Pediatric observation ward (OW) is the area where the patient can be monitored or have early investigation/management and observe part of emergency department (ED); patients are admitted to this area with an expectation of stay and discharge within 24 hours [1] [2] [3]. Some children need to be observed for a period of time before deciding based on the severity and progression of patient's condition for appropriate management, thus the observation ward was beneficial in preventing avoidable hospitalizations. Some studies evaluate the used of pediatric OW by pediatric ED for common pediatric illness, such as croup, asthma, gastroenteritis, dehydration, poisoning and seizure [4]. Confined to respiratory problem, including croup, the OW can be prevent admission to inpatient ward which rate of transfer patient from OW to ward ranges from 1.3\% - 5.6\% [5] [6] [7]. The OW can be reduced the high volume of patients in ED, OW increasing demands, overcrowding, and prolonged stay [8] [9] [10]. There have study of the utility of the benefit and characteristic from other country [11] [12] [13] [14]. There are not many pediatric OWs in Thailand, and then the utility of Pediatric OW is not wild report. Length of stay (LOS) is one of the most common used for OW outcome measurement [15]. One study was showed that the LOS is one of the most common indicators for measuring the ED performance [16]. The prolonged stay in OW may be associated with patients' dissatisfaction, decreased efficacy, premature departure and adverse patient outcome [17]. There have been studies reporting the predictor associated with LOS in OW [18] [19] [20]. Therefore, the objective of this study to report the characteristics of pediatric OW and examine factors associated with prolonged OW stay (LOS $>24$ hours) in the pediatric OW of an urban university hospital in Thailand.

\section{Methods}

\subsection{Participants}

This is a retrospective study of children 15 years or younger who admit to Pediatric OW at Faculty of Medicine Ramathibodi Hospital, Bangkok, Thailand during January 2014 to June 2015. Ramathibodi Hospital is the urban university hospital composed of 1500 beds. We have around 200 beds for pediatric. The annual ED pediatric visit rate is about 12,000 cases per year [21]. The pediatric 
OW has 12 beds. The Pediatric OW admitted patient ages more than 1 month until 15 years old. The criteria of admission based on patients' condition that not required the intensive care can be admit and the decision making; weather admit to inpatient ward or discharge will decided within 24 hours. The data were corrected from medical record of patients who admitted in OW. The demographic data of patients were collected included: age, sex, diagnosis, LOS, disposition (admit to inpatient ward or discharge).

\subsection{Statistical Analysis}

The sample characteristic was described using percent, mean, and SD for continuous variables. The categorized variable were compared and determined by Chi-square test. Mann-Whitney $U$ test were used for compare the differences between two independence groups, and the differences of more than two groups were used Kruskal-Wallis one-way ANOVA test. All statistical analyses were performed using SPSS version 17.0 (IBM cooperation, Armonk, New York).

\subsection{Ethical Consideration}

This study was performed with approval from the Institutional review Board (IRB) of Faculty of Medicine Ramathibodi Hospital, Mahidol University, Bangkok, Thailand.

\section{Results}

There were 670 patients admitted at OW during the study period. The most common top 5 diagnosis were respiratory problem (32\%), gastrointestinal problem (29\%), infectious disease (11\%), neurological (7\%), and dental problem (6\%) (Table 1). The characteristic of patients were showed in Table 2. Fifty three percent were male, age of patients range from 3 month to 20 years and overall mean length of stay in OW was 61 hours. Most of patients were directly admitted from Emergency room (49\%). After admit at OW, the majority of patients were discharge home $602 / 670$ cases (90\%), and $10 \%$ (68/670 cases) were admit to inpatient ward $(\mathrm{p}<0.001)$ (Table 2$)$. There were 552 patients $(82 \%)$ had prolong OW more than 24 hour. Compare the factors in both group, we found that the associated factor for prolong OW stay was the age of patient, seem to be younger in the prolonged stay group (median age of 4.25 years versus 3.42 years, $\mathrm{p}=$ 0.04 ) respectively (Table 2 ). We further analysis by age group distribution into age group less than 1 year, 1 - 5 years, 5 - 10 years, 10 - 15 years and more than 15 years. The result found that younger patient was factor associate with prolonged stay in OW $(\mathrm{p}<0.001)$ (Table 3$)$.

\section{Discussion}

Our study explores the characteristic and factors associated with prolong length of stay (LOS $>24$ hours) in the pediatric observation ward. There were 670 patients admitted at OW during the study period. The overall LOS in OW in previous study [22] report median LOS of 8.4 hours and range of LOS between 12 - 
Table 1. Diagnosis.

\begin{tabular}{cc}
\hline Diagnosis group (problems) & $\mathrm{n}=670$, (percent) \\
\hline Respiratory $^{*}$ & $214(32 \%)$ \\
Gastrointestinal $^{* *}$ & $194(29 \%)$ \\
Infectious disease $^{*}$ & $74(11 \%)$ \\
Neurological & $47(7 \%)$ \\
Dental & $40(6 \%)$ \\
Rheumatology & $34(5 \%)$ \\
Nephrology & $34(5 \%)$ \\
Oncology & $20(3 \%)$ \\
Other & $13(2 \%)$ \\
\hline
\end{tabular}

* Include viral pneumonia, acute bronchitis, and acute asthmatic attack; ${ }^{* *}$ Include viral intestinal infection and acute gastroenteritis.

Table 2. Characteristic and compared Length of Stay (LOS) less than 24 hours and more than 24 hours. Emergency Department (ED), Outpatient department (OPD).

\begin{tabular}{ccccc}
\hline \multicolumn{2}{c}{ Variables/LOS } & $\begin{array}{c}\text { LOS }<24 \text { hours } \\
(\mathrm{n}=118)\end{array}$ & $\begin{array}{c}\text { LOS }>24 \text { hours } \\
(\mathrm{n}=552)\end{array}$ & p-value \\
\hline \multirow{2}{*}{ Gender } & (n, percent) & & & \\
& Male & $57(48.31)$ & $299(54.17)$ & $0.24(\mathrm{a})$ \\
& Female & $61(51.69)$ & $253(45.83)$ & \\
Age & Mean $( \pm)$ SD & $5.7( \pm 4.7)$ & $4.8( \pm 4.0)$ & 0.04 (b) \\
& Median & 4.25 & 3.42 & $0.13(\mathrm{a})$ \\
Admit from & Min, Max & $(0.25,20)$ & $(0.16,19)$ & \\
& (n, percent) & & & \\
& ED & $63(53.39)$ & $266(48.19)$ & $<0.001$ (a) \\
& OPD & $42(35.59)$ & $246(44.57)$ & \\
Patient & Other & $13(11.02)$ & $40(7.25)$ & \\
Discharge & (n, percent) & & $516(93.48)$ & \\
& Home & $86(72.88)$ & $36(6.52)$ & \\
\hline
\end{tabular}

(a) Chi-square test, (b) Mann-Whitney U test.

Table 3. Compare age group distribution and Length of Stay (LOS) less than 24 hours and more than 24 hours.

\begin{tabular}{cccc}
\hline Variables/LOS & & LOS $<24$ hours & LOS $>24$ hours \\
\hline Age group distribution & (n, percent) & $(\mathrm{n}=118)$ & $(\mathrm{n}=552)$ \\
\hline$<1 \mathrm{y}$ & $11(9.32)$ & $70(12.68)$ \\
$1-5$ yrs. & $58(49.15)$ & $285(51.63)$ \\
$5-10$ yrs. & $24(20.34)$ & $126(22.83)$ \\
$10-15$ yrs. & $21(17.80)$ & $63(11.41)$ \\
& $>15$ yrs. & $4(3.39)$ & $8(1.45)$ \\
& P-value for trend & 0.76 & $<0.001$ \\
\hline
\end{tabular}

*Kruskal-Wallis one-way ANOVA. 
23 hours, compare to our study report mean LOS of OW was 61 hours, which longer than previous study. This maybe explain by the utilization purpose of our OW was different from previous study that admit all patient from ED. For our study, the patient whom admit to OW can come from other department apart from $\mathrm{ED}$, such as pediatric outpatient department (OPD) including patient schedule for procedure, or from general ward that had overcrowding of the bed. Therefore, some conditions or illness of patients need to observe or treatment more than 24 hours in OW. The most common diagnosis in patient of our study were respiratory problem including viral pneumonia, acute bronchitis, and acute asthmatic attack follow by gastrointestinal problem(viral intestinal infection and acute gastroenteritis) which are total of $61 \%$ of all diagnosis. These are the same categorized of illness [4] [23] which are respiratory and gastrointestinal system for the common pediatric illness that admits to OW. The majority of patients were discharge home $602 / 670$ cases $(90 \%)$, which are the same tend of previous study [23] and 10\% (68/670 cases) were admit to inpatient ward. There were 552 patients $(82 \%)$ had prolong OW more than 24 hours. Compare to the previous study [24] that LOS greater than 24 hours was $31.3 \%$. To explore the cause of this finding, we compare the factors for prolong LOS in both group, and found that the associated factor for prolong OW stay was the age of patient which seem to be younger in the prolonged stay group (median age of 4.25 years versus 3.42 years, $\mathrm{p}=0.04$ ) (Table 2 ). We explore more specific in age group by categorized age group distribution into group of age less than 1 year, 1 - 5 years, 5 - 10 years, 10 - 15 years and more than 15 years (Table 3 ). The result show that, age of patient was not the factor in group of patient that stay in OW less than 24 hours ( $p$ $=0.76$ ), whereas in the group of prolonged stay more than 24 hours, age of patient was the significant factors for prolonged stay in OW $(\mathrm{p}<0.001)$. Due to the criteria for admit to our OW that the age of patient should older than 1 month, therefore, maybe difficult to compare to previous study [24] that OW can admit patient age less than 1 month. But the result of subgroup analysis for age group distribution (Table 3) shows the same trend of previous study [24] that more younger age was the factor for prolong OW stay by compare to age group less than 28 days; with the age group 28 days to 3 month (OR 1.87) and the age group of 3 month to 12 month (OR 1.83) respectively. This result leads to the same direction that the younger patient associated with prolonged stay in observation ward.

\section{Conclusion}

This was the report of factor of prolonged stay in pediatric OW. The younger patient was the associated factor for prolonged stay in OW. Understanding this related issue will be the starting points for assessment patients carefully before admitting to OW for improving efficiency and quality of care in pediatric OW.

\section{Limitations}

This is the single institution and short period of study. The result of this study 
maybe does not reflex to the overall of OW across country. Multicenter and longer period of study should be done in the future.

\section{Conflicts of Interest}

The authors declare no conflicts of interest regarding the publication of this paper.

\section{References}

[1] Levett, I., Berry, K. and Wacogne, I. (2006) Review of a Paediatric Emergency Department Observation Unit. Emergency Medicine Journal, 23, 612-613. https://doi.org/10.1136/emj.2005.029470

[2] Wiley, J.F. (2001) Pediatric Clinical Decision Units: Observations Past, Present, and Future. Clinical Pediatric Emergency Medicine, 2, 247-252. https://doi.org/10.1016/S1522-8401(01)90032-1

[3] Alpern, E.R., Calello, D.P., Windreich, R., Osterhoudt, K. and Shaw, K.N. (2008) Utilization and Unexpected Hospitalization Rates of a Pediatric Emergency Department 23-Hour Observation Unit. Pediatric Emergency Care, 24, 589-594. https://doi.org/10.1097/PEC.0b013e3181850c80

[4] Scribano, P.V., Wiley, J.F. and Platt, K. (2001) Use of an Observation Unit by a Pediatric Emergency Department for Common Pediatric Illnesses. Pediatric Emergency Care, 17, 321-323. https://doi.org/10.1097/00006565-200110000-00001

[5] Greenberg, R.A., Dudley, N.C. and Rittichier, K.K. (2006) A Reduction in Hospitalization, Length of Stay, and Hospital Charges for Croup with the Institution of a Pediatric Observation Unit. The American Journal of Emergency Medicine, 24, 818-821. https://doi.org/10.1016/j.ajem.2006.05.003

[6] Cooke, M.W., Higgins, J. and Kidd, P. (2003) Use of Emergency Observation and Assessment Wards: A Systematic Literature Review. Emergency Medicine Journal, 20, 138-142. https://doi.org/10.1136/emj.20.2.138

[7] Marx, A., Torok, T.J., Holman, R.C., Clarke, M.J. and Anderson, L.J. (1997) Pediatric Hospitalizations for Croup (Laryngotracheobronchitis): Biennial Increases Associated with Human Parainfluenza Virus 1 Epidemics. The Journal of Infectious Diseases, 176, 1423-1427. https://doi.org/10.1086/514137

[8] Hoot, N.R. and Aronsky, D. (2008) Systematic Review of Emergency Department Crowding: Causes, Effects and Solutions. Annals of Emergency Medicine, 52, 126-136.E1. https://doi.org/10.1016/j.annemergmed.2008.03.014

[9] LeBaron, J., Culberson 3rd, M.C., Wiley 2nd, J.F. and Smith, S.R. (2010) "Be Quick": A Systems Response to Overcrowding in the Pediatric Emergency Department. Pediatric Emergency Care, 26, 808-813. https://doi.org/10.1097/PEC.0b013e3181fa8853

[10] American Academy of Pediatrics (AAP) Committee on Pediatric Emergency Medicine (2004) Overcrowding Crisis in Our Nation's Emergency Department: Is Our Safety Net Unraveling? Pediatrics, 114, 878-888. https://doi.org/10.1542/peds.2004-1287

[11] Broquetas, J.M., Pedreny, R., Martinez-Llorens, J.M., Sellarés, J. and Gea, J. (2008) Short-Stay Respiratory Unit: A New Option for Inpatient Care [in Spanish]. Archivos de Bronconeumología, 44, 252-256. https://doi.org/10.1016/S1579-2129(08)60040-3 
[12] Goodacre, S.W. (1998) Role of the Short Stay Observation Ward in Accident and Emergency Department in the United Kingdom. Emergency Medicine Journal, 15, 26-30. https://doi.org/10.1136/emj.15.1.26

[13] Jelinek, G.A. and Galvin, G.M. (1989) Observation Wards in Australian Hospitals. Medical Journal of Australia, 151, 80-83. https://doi.org/10.5694/j.1326-5377.1989.tb101166.x

[14] Bray, T. (1999) Utilization of a Short Stay Unit in a Paediatric Emergency Department. Australian Emergency Nursing Journal, 2, 34-36. https://doi.org/10.1016/S1328-2743(99)80017-0

[15] Macy, M.L., Kim, C.S., Sasson, C., Lozon, M.M. and Davis, M.M. (2010) Pediatric Observation Units in the United States: A Systematic Review. Journal of Hospital Medicine, 5, 172-182. https://doi.org/10.1002/jhm.592

[16] Hung, G.R. and Chalut, D. (2008) A Consensus-Established Set of Important Indicators of Pediatric Emergency Department Performance. Pediatric Emergency Care, 24, 9-15. https://doi.org/10.1097/pec.0b013e31815f39a5

[17] Brillman, J., Mathers-Dunbar, L., Graff, L., Joseph, T., Leikin, J.B., Schultz, C., et al. (1995) Management of Observation Units. American College of Emergency Physicians. Annals of Emergency Medicine, 25, 823-830. https://doi.org/10.1016/S0196-0644(95)70215-6

[18] Goldman, R.D., Amin, P. and Macpherson, A. (2006) Language and Length of Stay in the Pediatric Emergency Department. Pediatric Emergency Care, 22, 640-643. https://doi.org/10.1097/01.pec.0000227865.38815.ec

[19] Gorelick, M.H., Yen, K. and Yun, H.J. (2005) The Effect of In-Room Registration on Emergency Department Length of Stay. Annals of Emergency Medicine, 45, 128-133. https://doi.org/10.1016/j.annemergmed.2004.08.041

[20] Hillier, D.F., Parry, G.J., Shannon, M.W. and Stack, A.M. (2009) The Effect of Hospital Bed Occupancy on Throughput in the Pediatric Emergency Department. Annals of Emergency Medicine, 53, 767-776.E3. https://doi.org/10.1016/j.annemergmed.2008.11.024

[21] Pandee, U., Vallipakorn, S.A. and Plitponkarnpim, A. (2015) The Profile of Pediatric Patients Visit Emergency Department at Urban University Hospital in Thailand. Journal of the Medical Association of Thailand, 98, 761-767.

[22] Leduc, K., Haley-Andrews, S. and Rannie, M. (2002) An Observation Unit in a Pediatric Emergency Department: One Children's Hospital's Experience. Journal of Emergency Nursing, 28, 407-413. https://doi.org/10.1067/men.2002.126669

[23] Zebrack, M., Kadish, H. and Nelson, D. (2005) The Pediatric Hybrid Observation Unit: An Analysis of 6477 Consecutive Patient Encounters. Pediatrics, 115, e535-e542. https://doi.org/10.1542/peds.2004-0391

[24] Xie, J., Lin, Y. and Kissoon, N. (2013) Factors Associated with Prolonged Stay in a Pediatric Emergency Observation Unit of an Urban Tertiary Children's Hospital in China. Pediatric Emergency Care, 29, 183-190.

https://doi.org/10.1097/PEC.0b013e3182809b64 